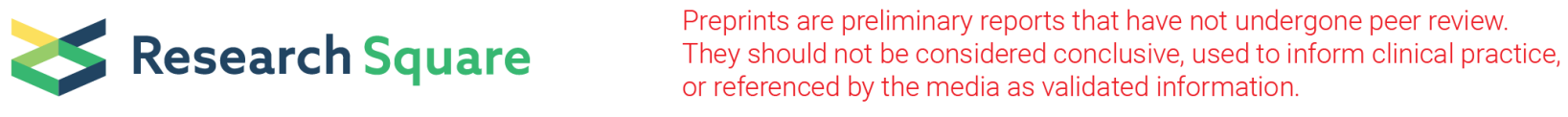

\title{
Changing Lake Ice Intermittency in the Northern Hemisphere
}

Grace Liu ( $\square$ graceliu@princeton.edu )

Princeton University https://orcid.org/0000-0001-7405-9687

Nadir Jeevanjee

Geophysical Fluid Dynamics Laboratory

Sirisha Kalidindi

Princeton University

Gabriel A Vecchi

Princeton University

\section{Research Article}

Keywords: climate change, intermittent lake ice, lake freeze, lake ice phenology

Posted Date: November 15th, 2021

DOI: https://doi.org/10.21203/rs.3.rs-1070785/v1

License: (1) This work is licensed under a Creative Commons Attribution 4.0 International License. Read Full License 


\section{Abstract}

As the global climate warms, lakes are expected and have been observed to experience changes in seasonal ice cover. Previous research has observed decreasing freeze durations, but relatively few studies have investigated the impact of climate change on lake ice intermittency - the tendency of lakes to freeze over in some years but not others. Here we conduct an analysis of a lake dataset that includes nineteen intermittent ice-covered lakes in the northern hemisphere. We use logistic and binomial regression to model the relationship between historical climate changes and freeze events, with $\log \mathrm{CO}_{2}$ concentration and mean winter temperature as covariates. Across the lakes, we observe a decrease in freeze probability and years with freeze events, with nine out of nineteen lakes showing a significant relationship between freeze years and $\log \mathrm{CO}_{2}$ concentration. Additionally, we find that mean winter temperature can be a simple, readily accessible predictor for intermittent lake freeze. We also examine Lake Carnegie in Princeton, NJ as a case study, taking into account both quantitative data and anecdotal evidence, and find that the probability of ice skating has decreased from nearly 1 to 0.2 over the past century. Accordingly, local newspaper archives semantically suggest that local expectations for lake freezing have reversed over the last century as a societal response to climate change.

\section{Introduction}

Annual lake freezing holds ecological, economic, and cultural significance for many populations (Kling et al. 2003). Ice cover is essential for recreational activities such as ice skating (Brammer et al. 2015), ecological processes such as phytoplankton growth (Weyhenmeyer 2001), and is even a part of religious traditions (Arakawa 1954). However, climate change has resulted in freshwater ice loss, with studies on lake ice phenology, the study of seasonal freezing patterns, revealing trends toward later freeze dates and earlier ice break-up dates (Magnuson et al. 2000; Hodgkins et al. 2002; Benson et al. 2012). Research on local climate indicators has also shown high interannual variability of ice break-up dates in the past century(Betts 2011).

Lakes are referred to as either annual ice-covered or intermittent ice-covered based on their winter freeze behavior. Annual ice-covered lakes are defined to freeze consistently every year while intermittent ice-covered lakes have had at least one winter without complete ice cover since 1970 (Sharma et al. 2019; henceforth S19). Most studies have focused on changes in freeze dates, thaw dates, or ice duration, often treating intermittency as a data anomaly (Jensen et al. 2007; Benson et al. 2012). Thus, there is an overall dearth of research on intermittent ice-covered lakes in the literature, and more research on intermittent ice-covered lakes is needed to thoroughly understand the impacts of climate change on freshwater systems.

In this vein, S19 investigated intermittency trends and created projections for the number of intermittent ice-covered lakes given global warming scenarios. While S19 focus on predicting the present and future distribution of intermittent ice-covered lakes globally, the present paper highlights historic trends in intermittency. Our motivation for studying these trends stems from the binary nature of lake ice intermittency (lakes are recorded as having either completely frozen over or not in a given year), making intermittency a concrete and thus easily perceived potential indicator of local climate change. Furthermore, ice freeze integrates weather over a season, increasing the signalto-noise ratio compared to other tangible events like extreme weather. These merits make lake ice freeze a uniquely tangible lens for studying climate change, especially in low-elevation continental interiors where other integrated climate impacts (e.g. glacier retreat, sea level rise) do not apply.

Our analysis of lake ice intermittency relies largely on in-situ freeze records for intermittent ice-covered lakes within the NSIDC Global Lake and River Ice Phenology Database. Additionally, however, we highlight Princeton's Lake Carnegie as a case study, using a new approach to reconstruct freeze records from newspaper archives. This approach allows us to identify trends in Lake Carnegie's intermittency, as well as a corresponding change in expectations of lake freeze, as embodied in news article narratives.

\section{Methods And Data}

We obtained freeze time series from the NSIDC Global Lake and River Ice Phenology Database (Benson 2002), which contains ice-on and ice-off records for over 500 lakes across the Northern Hemisphere but only contains records for 17 intermittent ice-covered lakes. We reached out to data contributors and acquired data for two more intermittent ice-covered lakes and updated the time series for three lakes. Figure 1 shows the geographic distribution of the 19 intermittent lakes, and Table 1 shows characteristics for each lake, including the length of the freeze records.

Regression on $\mathrm{CO}_{2}$ concentration has been used previously to define trends on ENSO indices (Oldenborgh et al. 2021). Furthermore, Sharma et al. identify $\mathrm{CO}_{2}$ concentration and local, seasonal air temperature to be the most important drivers of freeze and break-up dates of lake ice (Sharma et al. 2016). Thus, we analyzed intermittent ice time series individually, fitting a logistic regression to each lake freeze time 
series conditioned on log global $\mathrm{CO}_{2}$ concentration, acquired from the Last Millennium Ensemble (LME) (Otto-Bliesner et al. 2016). We used data from the LME because the time series of some lakes exceeded the length of observational atmospheric $\mathrm{CO}_{2}$ records. We also analyzed the aggregate data of all the available intermittent lakes by fitting a binomial regression to the time series of aggregate freeze proportion, again using log global $\mathrm{CO}_{2}$ concentration as our covariate. We used $\log \mathrm{CO}_{2}$ concentration rather than $\mathrm{CO}_{2}$ concentration because radiative forcing caused by carbon dioxide has a logarithmic relationship with $\mathrm{CO}_{2}$ concentration (Jeevanjee et al. 2021). The logistic and binomial regression fit calculations are performed in $\mathrm{R}$ using the freely available gamlss package (Stasinopoulos and Rigby 2007). Logistic regression determines the probability of freeze by modeling the binary response variable as a Bernoulli distribution and passing the input through a logit function. Similarly, binomial regression fits the proportion of lake freeze by modeling the response variable as a binomial distribution. The logit function in both cases is given by:

$\hat{y}=\frac{e^{a x+b}}{1+e^{a x+b}}$

where $\mathrm{x}$ is the input vector of $\log \mathrm{CO}_{2}$ concentration and $\hat{y}$ is the predicted probability of freeze.

The cross-entropy loss function to be minimized is given by (Jurafsky and Martin 2020):

\section{$L_{C E}(\hat{y}, y)=-[y \log \hat{y}+(1-y) \log (1-\hat{y})]$}

Where $\hat{y}$ is the predicted probability of freeze, and $y$ is the actual binary freeze response. The loss function is the log likelihood function with a flipped sign.

In addition to observing the change in freeze probability and freeze proportion with respect to $\mathrm{CO}_{2}$ concentration, we also investigate winter temperature as a potential predictor of lake freeze. Winter temperature has been shown to be an important factor in ice break-up trends (Brown and Duguay 2010; Sharma et al. 2016). In contrast to break-up dates, freeze dates have been shown to be highly variable and thus difficult to determine a clear trend (Brown and Duguay 2010). However, sparse research has been done to analyze the explanatory power of winter temperature with regard to binary freeze responses rather than freeze and break-up dates. Therefore, we analyzed winter temperature as a driver of lake freeze for intermittent ice-covered lakes. For each lake in the NSIDC dataset, we extracted gridded data for winter temperature from the Berkeley Earth dataset (Rohde and Hausfather 2020) and fitted a logistic regression curve to the freeze data with winter temperature as a covariate. The length of the temperature record extends from 1850 to the present. so the full time series could not be considered for some lakes. We computed the McFadden pseudo- $\mathrm{R}^{2}$ statistic, which measures the reduction in maximized log-likelihood rather than the proportion of explained variance. (Mittlböck and Schemper 1996), for each lake to evaluate and compare the explanatory power of winter temperature in determining freeze years.

In addition, we studied Princeton's Lake Carnegie as a case of particular interest, also fitting a logistic regression on $\mathrm{CO}_{2}$ concentration to the time series of ice skating on Lake Carnegie. Because Lake Carnegie is not in the NSIDC database, we used a new approach to reconstruct Lake Carnegie based on documented ice-skating in records, using historical newspapers from the Papers of Princeton archive (Papers Of Princeton). Years in which newspaper articles mentioned ice skating, hockey, thick ice, and other mentions of complete freeze were recorded as years with ice skating, and years in which newspaper articles mentioned that the lake did not freeze over during the winter were recorded as years without ice skating. Years that fell into neither category are considered ambiguous, and were excluded from the regression analysis. This method allowed us to reconstruct a dataset of years in which Lake Carnegie froze over (or failed to freeze over) for ice skating. Additionally, this unique approach provided insight into how people experience climate change, adding a personal dimension to our quantitative analysis.

\section{Results}

Figure 2 shows the individual time series and logistic regression curve for four geographically distinct lakes in the dataset. We observe a decrease in freeze events and freeze probability over time. The overall trend suggests that lakes are experiencing more years without complete ice-cover. Additionally, these lakes appear to be in different stages of the transition from consistent annual ice cover to intermittent ice cover. For example, Lake Vättern shows a shift from frequent annual freezing to a regime without winter freeze. Lake Champlain appears to be in the middle of this shift, while other lakes in the dataset have only begun the transition to intermittency.

Table 1 shows geographical characteristics for each of the 19 intermittent lakes, as well as some statistics regarding record length and freeze trends. The columns for early and late freeze proportion represent the proportion of freeze years within the first 20 years and last 20 
years of the time series, respectively. Most of the freeze records extend into the early twenty-first century. These results show that 17 out of the 19 lakes show a lower freeze proportion in the last 20 years of the time series than the first 20 years.

In order to give a more comprehensive overview of the freeze trends across lakes, we computed the aggregate freeze proportion over time: the number of lakes that froze in a given year divided by the number of lakes with freeze data in that year. We then fitted a binomial regression model to the aggregate freeze proportion data, conditioned against $\log \mathrm{CO}_{2}$ concentration. Accordingly, figure $3 \mathrm{~b}$ shows the freeze proportion time series of all the available intermittent lakes. We find that the proportion of intermittent ice-covered lakes that freeze in a given year trends downward after 1960, and the variability of freeze proportion increases over the course of the century.

Figure 3a shows the logistic regression curves for the 19 intermittent ice-covered lakes fitted on log $\mathrm{CO}_{2} \mathrm{Concentration}$ Out of the 19 lakes, 17 lakes show a downward trend of freeze probability, generalizing the pattern of decreasing freeze years observed in figure 2 . Table 1 lists the coefficient and p-value of the logistic regression fits for each lake. The fit for 9 of the lakes was significant at the $5 \%$ level, and the 2 lakes with positive trends did not have a significant p-value. This result implies that, for these 9 lakes, the climate change signal overshadows the natural year-to-year variability in lake freeze. However, some lakes do not show a significant relationship with log $\mathrm{CO}_{2}$ concentration, which could be due to a lack of data (short record length) or because these lakes freeze almost every year, such that nofreeze years are rare and we hypothesize they are dominated by internal variability rather than the climate change signal.

Table 1. Intermittently Freezing Lakes in the Northern Hemisphere 


\begin{tabular}{|c|c|c|c|c|c|c|c|c|c|c|}
\hline lakename & country/state & latitude & longitude & $\begin{array}{l}\text { record } \\
\text { length }\end{array}$ & $\begin{array}{l}\text { early } \\
\text { freeze } \\
\text { prop }\end{array}$ & $\begin{array}{l}\text { late } \\
\text { freeze } \\
\text { prop }\end{array}$ & $\begin{array}{l}\text { co2 } \\
\text { coeffictient }\end{array}$ & $\begin{array}{l}\mathrm{p}- \\
\text { value }\end{array}$ & intercept & contributor \\
\hline Lake Suwa & Japan/Nagano & 36.15 & 138.08 & 560 & 1.00 & 0.50 & -9.655 & $<0.001$ & 57.506 & \\
\hline Lake Geneva & US/WI & 42.57 & -88.48 & 143 & 1.00 & 0.90 & -42.080 & 0.117 & 250.580 & \\
\hline Otsego Lake & US/NY & 42.76 & -74.89 & 174 & 1.00 & 0.80 & -43.280 & 0.0352 & 259.180 & $\begin{array}{l}\text { Stewart, } \\
\text { Kenton }{ }^{1}\end{array}$ \\
\hline Oneida Lake & US/NY & 43.21 & -75.91 & 176 & 1.00 & 0.95 & -33.060 & 0.242 & 198.600 & \\
\hline Lake George & US/NY & 43.62 & -73.55 & 104 & 1.00 & 0.95 & -23.190 & 0.236 & 140.600 & $\begin{array}{l}\text { Stewart, } \\
\text { Kenton }{ }^{1}\end{array}$ \\
\hline $\begin{array}{l}\text { Big Green } \\
\text { Lake }\end{array}$ & US/WI & 43.80 & -89.03 & 67 & 1.00 & 0.95 & -46.360 & 0.282 & 276.900 & \\
\hline Sebago Lake & US/ME & 43.84 & -70.57 & 181 & 1.00 & 0.70 & -10.098 & $<0.001$ & 60.958 & \\
\hline $\begin{array}{l}\text { Lake } \\
\text { Champlain }\end{array}$ & US/NY & 44.31 & -73.33 & 186 & 0.95 & 0.40 & -16.659 & $<0.001$ & 97.285 & \\
\hline $\begin{array}{l}\text { Grand } \\
\text { Traverse Bay }\end{array}$ & US/MI & 44.75 & -85.62 & 146 & 0.85 & 0.65 & -8.297 & 0.01 & 49.049 & \\
\hline Gull Lake & US/MI & 44.91 & -79.35 & 96 & 0.90 & 0.95 & 4.420 & 0.566 & -22.237 & $\begin{array}{l}\text { Hamilton, } \\
\text { Stephen }{ }^{1}\end{array}$ \\
\hline Green Bay & US/MI & 45.00 & -87.64 & 74 & 1.00 & 0.95 & -46.940 & 0.262 & 274.120 & \\
\hline $\begin{array}{l}\text { Lake } \\
\text { Superior }\end{array}$ & US/WI & 46.81 & -90.81 & 155 & 1.00 & 0.90 & -30.150 & 0.099 & 181.240 & \\
\hline $\begin{array}{l}\text { Lake } \\
\text { Balaton }^{2}\end{array}$ & Hungary & 46.88 & 17.84 & 33 & 1.00 & 1.00 & 10.770 & 0.702 & -59.080 & \\
\hline Lunz & Austria & 47.85 & 15.05 & 74 & 1.00 & 0.90 & -25.920 & 0.128 & 156.940 & $\begin{array}{l}\text { Sharma, } \\
\text { Sapna }^{3}\end{array}$ \\
\hline $\begin{array}{l}\text { Lake } \\
\text { Mueggelsee }^{2}\end{array}$ & Germany & 52.44 & 13.65 & 20 & 1.00 & 0.80 & -33.400 & 0.366 & 197.870 & \\
\hline Nehmitzsee $^{2}$ & Germany & 53.13 & 12.98 & 29 & 1.00 & 0.70 & -60.590 & 0.044 & 355.010 & \\
\hline Lake Vättern & Sweden & 58.33 & 14.49 & 70 & 0.75 & 0.10 & -16.990 & $<0.001$ & 98.330 & \\
\hline Randsfjorden & Norway & 60.52 & 10.36 & 70 & 1.00 & 0.75 & -21.252 & 0.006 & 127.454 & $\begin{array}{l}\text { Sharma, } \\
\text { Sapna }^{3}\end{array}$ \\
\hline Lake Mjøsa & Norway & 60.77 & 11.02 & 125 & 0.90 & 0.65 & -9.796 & 0.004 & 57.577 & \\
\hline
\end{tabular}

${ }^{7}$ Time series updated through direct correspondence

${ }^{2}$ For lakes with a record length of less than 40 years, early freeze proportion and late freeze proportion are calculated using the first 10 years and last 10 years.

${ }^{3}$ Time series received through direct correspondence

\subsection{Winter temperature as a covariate of lake freeze}

$\mathrm{CO}_{2}$ concentration as an explanatory variable has a trend but no year to year variability. In contrast, mean annual winter temperature as an explanatory variable could account for both the trend and year to year variability in lake freeze events. Thus, in addition to the analysis of freeze over $\log \mathrm{CO}_{2}$ concentration, we investigated the importance of winter temperature in determining freeze years. We fitted a logistic regression to each of the lake time series conditioned on the mean winter temperature of the lake's grid box in the Berkeley Earth dataset. Because some of the freeze time series had only one or two years without freeze, we narrowed the analysis down to time series with multiple no-freeze years. The arbitrary cutoff of four years was chosen due to the fact that there was a natural separation in the data 
between the lakes with fewer than four years without freeze and lakes with greater than four years without freeze. The distribution of the logistic regression thresholds for these seven lakes had a mean of $-3.07^{\circ} \mathrm{C}$, a median of $-3.49^{\circ} \mathrm{C}$, and an interquartile range of $3.36^{\circ} \mathrm{C}$.

Figure 4 shows scatterplots of mean winter temperature and freeze over time for four lakes in the dataset as well as the logistic regression threshold for classifying years as freeze or no-freeze. These four lakes were selected because they had a relatively high number of data points and a higher number of years without freeze. The McFadden pseudo- $\mathrm{R}^{2}$ values for these four lakes were $0.32,0.31,0.43$, and 0.50 for Lake Champlain, Lake Suwa, Lake Vättern, and Lake Mjøsa, respectively. Thus, these lakes represent a range of geographic locations and goodness of fit. The steepness of the trend lines also varies, indicating that some regions have warmed faster than others, though each of the lakes shows an increase in years without freeze events. Overall, these plots suggest that mean winter temperature can be used as a simple predictor of intermittent lake freeze, linking the trends in freezing from Figures 2 and $3 a$ to climate change. However, the amount of freeze variation explained differs based on the individual lake.

We also investigated whether the intermittency of a lake depends more on its mean winter temperature or the severity of warming (i.e., the steepness of the trend line). We plotted the density of mean winter temperatures and winter temperature trends for intermittent ice-covered lakes and annual ice-covered lakes (Fig. 5). We see a separation between the two categories with respect to mean winter temperature, but not with respect to winter temperature trends. This distinction suggests that the climatological mean winter temperature is a better predictor of freeze than the geographical variation in severity of warming. Additionally, the mean winter temperatures of the intermittent ice-covered lakes intersect the mean intermittency threshold $\left(\sim-3.07^{\circ} \mathrm{C}\right)$, whereas nearly all of the annual ice-covered lakes had mean winter temperatures lower than the threshold.

\subsection{Case Study - Lake Carnegie}

Currently, most knowledge of winter limnology comes from in situ data observations (Sharma et al. 2020). However, there has been a decline in availability of in situ observations since the 1980s, so ice networks have been supplemented with satellite data and physical lake models(Latifovic and Pouliot 2007; Bernhardt et al. 2012; Weber et al. 2016). In order to advance working knowledge of lake ice phenology, it may also be worthwhile to supplement the declining in situ data by utilizing historical records of lake events. Therefore, we used a new approach to reconstruct Lake Carnegie ice-skating records using newspaper archives. Figure 6 shows the time series of years with and without safe ice skating. The logistic regression curve covaried against log $\mathrm{CO}_{2}$ concentration indicates a steep decrease in the probability of safe ice skating over the last century, from approximately 1.0 to 0.20 with a $p$-value less than 0.001 .

We must also consider that other confounding factors, such as increased safety restrictions on ice skating and dredging of the lake may have contributed to the trend we see in decreased ice skating. For example, there is a sequence of three years without ice skating in the 1970s, right after the third and most recent dredging of the lake. A 1976 newspaper article from the Town Topics cites the fast-flowing current of the recently dredged lake as the reason for this period without solid freezing (1976a). However, despite the possible short-term impact of dredging on lake freeze, we notice that ice skating declines most rapidly after the 1990s. Thus, it is likely that both warming temperatures and increased skating safety restrictions have both contributed to this steep decline. It would be difficult to separate these two factors, especially since decreased expectations for safe ice conditions can amplify safety regulations. That is, the warming trend causes thinner ice and fewer days with safe ice skating, which could lead to more stringent safety measures, which in turn further impacts expectations about the frequency of safe ice skating.

In addition to demonstrating local impacts of warming, these archives provide insight into the socio-cultural effects of climate change. They suggest that not only are freeze events decreasing overall but also that climate change is changing people's expectations. Figures $6 a$ and 6c show newspaper excerpts from 1960 and 2007, respectively. In 1960, a no-freeze year was considered exceptional; in 2007, a freeze event was considered exceptional. Over the course of a few decades, ice skating has gone from a consistent winter pastime to an unanticipated yet pleasant surprise, and the local community has fully reversed its expectations in response to this aspect of climate change, adapting to a new normal. Thus, the anecdotal recollections are in accordance with the trend observed in the reconstructed dataset. Because ice skating is a communal activity, this change in skating frequency and expectation for skating suggests that climate change has had a tangible effect on quality of life in the past decades. Figure $6 \mathrm{~b}$ details nostalgic memories of skating on the lake in the past but further emphasizes the shift in expectations with the statement, "But we don't get the ice now." These anecdotal accounts add a human dimension to the analysis yet remain consistent with the quantitative data.

\section{Discussion And Conclusion}

This analysis shows a clear trend of fewer years with freeze events in intermittent ice-covered lakes in the Northern Hemisphere, which can be modeled using mean winter temperature. Because these data are uniquely discrete, they provide a simple and intuitive visualization of 
the effects of climate change on lacustrine systems. The decline of aggregate freeze proportion generalizes the trend observed in the individual case studies, further emphasizing the large-scale impact of warming on lakes. Additionally, the case study of ice skating on Lake Carnegie shows how dwindling freeze events have changed local residents' perceptions of normality.

The results highlight the importance of studying lake ice intermittency as an indicator of climate change. The mean logistic regression threshold for classifying lakes as annual or intermittent ice cover was $-3.07^{\circ} \mathrm{C}$. This threshold provides a starting point for identifying regions at risk for lake ice intermittency, with the caveats that the sample size is very small and that individual lakes exhibit a range of thresholds. Figure 8a maps the percent of years over 1881-2020 in which the Berkeley Earth winter (DJF) averaged temperature exceeded the $-3.07^{\circ} \mathrm{C}$ threshold in the northern hemisphere. The multi-color band represents large-scale regions with substantial intermittency potential, while areas with no years exceeding the threshold are likely to freeze over every year, and regions with all years exceeding the threshold are unlikely to freeze over at all. We note that there is likely to be substantial orographically-driven structure in surface temperature relevant to lake freeze below the spatial resolution of the Berkeley Earth surface temperature data $\left(0.25^{\circ}\right)$ in regions such as Japan. The narrowness of the band indicates that large-scale lake intermittency is likely restricted to a relatively small portion of the globe, with much of the globe being either unconducive to freeze or reliably below the temperature threshold. This restriction may help explain the observed distribution of intermittent lakes (Fig. 1) as well as the low ratio of intermittent to annual lakes in our dataset; we note that there is substantial correspondence between the observed locations of lake intermittency (Fig. 1) and regions with large-scale intermittency potential.

The observed change in large-scale intermittency potential is shown in Figure 8b, by mapping the change in percent of years exceeding the threshold between the period 1951-2020 and the period 1881-1950. The colored regions correspond to areas with lakes that may have transitioned from annual to intermittent ice-cover - we note that no regions in the Northern Hemisphere showed a decrease in lake intermittency potential. The observed regions of increased intermittency potential (Fig. 8b) are generally collocated with regions of historical intermittency potential (Fig. 8a), reflecting that large-scale spatial gradients in wintertime surface temperature substantially exceed historical warming. That is, although historical warming has increased the area with intermittency potential, there remain large swaths of the Northern Hemisphere in which mean wintertime surface temperatures consistently remained below the $-3.07^{\circ} \mathrm{C}$ threshold. Additionally, there are regions in which intermittent ice-covered lakes could have transitioned to lakes that no longer freeze over during the winter.

A simple analysis of the impact of a $2^{\circ} \mathrm{C}$ warming on intermittency potential is shown in Figure $8 \mathrm{c}$, by plotting the percent difference in years above the $-5.07^{\circ} \mathrm{C}$ threshold and those above a $-3.07^{\circ} \mathrm{C}$ over the $1881-2020$ period. A uniform surface warming leads to highly structured changes in large-scale intermittency potential, reflecting the large-scale climatological patterns of wintertime surface temperature: large-scale intermittency potential is not substantially changed in regions that are either substantially colder or substantially warmer than the threshold.. A comparison of Fig. $8 \mathrm{~b}$ and $8 \mathrm{c}$ indicates that uniform warming could lead to shifts in the spatial structure of regions at risk for lake ice-intermittency toward higher latitudes and continental interiors. Future research could identify regions that are susceptible to intermittent ice-cover with respect to factors other than winter temperature and investigate how intermittency will evolve with climate change.

While the other literature has detailed models for predicting freeze and thaw dates (Vavrus et al. 1996; Bernhardt et al. 2012), many of the predictors in these models (e.g. lake depth and meteorological parameters) are not readily accessible for the majority of lakes. However, this study demonstrates that winter temperature is a simple, potential predictor of freeze and is readily accessible for any coordinate grid via the Berkeley Earth dataset. This ease of access in combination with our new method of reconstructing freeze data with historical records provides a simple, generalizable process for analyzing freezing trends for intermittent ice-covered lakes.

We find that the explanatory power of winter temperature varies depending on the individual characteristics of the lake. While log $\mathrm{CO}_{2}$ concentration can partly account for the lake freeze changes associated with the warming trend, mean winter temperature can account for both the trend and some of the year to year variability. The difference in the goodness of fit between each lake could be due to other factors that affect year to year variability, such as precipitation, wind speed, and cloud cover, which are input variables for lake ice model simulations (Vavrus et al. 1996; Ménard et al. 2002). Future research could investigate the explained variance of these other factors on intermittent lake freeze. Additionally, there is a separation between the mean winter temperatures of intermittent ice-covered lakes and annual ice-covered lakes, compared to no separation between the slope of the temperature trends of the two types of lakes (Fig. 5). This difference suggests that, with regard to freeze, the climatological mean winter temperature is more important than the steepness of the warming trend in a given region. Further research could explore how lakes transition from annual ice-cover to intermittent ice-cover as warming may shift mean winter temperatures closer to the threshold. This investigation has far-reaching implications for local lake communities because lake freezing provides vital ecological, economic, and cultural ecosystem services (Arakawa 1954; Weyhenmeyer 2001; Kling et al. 2003; Brammer et al. 2015). 
Cultural ecosystem services, such as ice skating, are widely enjoyed by and relevant to the general public (Brammer et al. 2015), but are often overlooked within climate change research (Schröter et al. 2005). Therefore, our analysis of declining ice skating on Lake Carnegie provides insight into how climate change has impacted these underrepresented ecosystem services. The newspaper archives provide alternative means of understanding historical climate, giving a human perspective on how climate change affects cultural activities. By examining historical ice-skating records of Lake Carnegie, we observe a distinct reversal of expectations for freezing, both qualitatively in the newspaper archives and quantitatively with a drastic drop in the probability of ice skating. This two-way interaction between the anecdotal and instrumental evidence provides insight into personal and societal responses to warming. Therefore, this study serves as an indicator of declining public ecosystem services and societal adaptation to climate change in addition to its natural effects.

\section{References}

1. https://doi.org/10.1175/BAMS-D-14-00233.1

2. Arakawa H (1954) Fujiwhara on five centuries of freezing dates of Lake Suwa in the Central Japan. Arch Met Geoph Biokl B 6:152166. https://doi.org/10.1007/BF02246747

3. Benson B (2002) Global Lake and River Ice Phenology Database. https://doi.org/10.7265/N5W66HP8

4. Benson BJ, Magnuson JJ, Jensen OP, et al (2012) Extreme events, trends, and variability in Northern Hemisphere lake-ice phenology (1855-2005). Climatic Change 112:299-323. https://doi.org/10.1007/s10584-011-0212-8

5. Bernhardt J, Engelhardt C, Kirillin G, Matschullat J (2012) Lake ice phenology in Berlin-Brandenburg from 1947-2007: observations and model hindcasts. Climatic Change; Dordrecht 112:791-817. http://dx.doi.org/10.1007/s10584-011-0248-9

6. Betts AK (2011) Vermont Climate Change Indicators. Weather, Climate, and Society 3:106-115. https://doi.org/10.1175/2011WCAS1096.1

7. Brammer JR, Samson J, Humphries MM (2015) Declining availability of outdoor skating in Canada. Nature Clim Change 5:2-4. https://doi.org/10.1038/nclimate2465

8. Brown LC, Duguay CR (2010) The response and role of ice cover in lake-climate interactions. Progress in Physical Geography: Earth and Environment 34:671-704. https://doi.org/10.1177/0309133310375653

9. Hodgkins GA, James II IC, Huntington TG (2002) Historical changes in lake ice-out dates as indicators of climate change in New England, 1850-2000. International Journal of Climatology 22:1819-1827. https://doi.org/10.1002/joc.857

10. Jeevanjee N, Seeley JT, Paynter D, Fueglistaler S (2021) An Analytical Model for Spatially Varying Clear-Sky CO2 Forcing. Journal of Climate 1:1-55. https://doi.org/10.1175/JCLI-D-19-0756.1

11. Jensen OP, Benson BJ, Magnuson JJ, et al (2007) Spatial analysis of ice phenology trends across the Laurentian Great Lakes region during a recent warming period. Limnology and Oceanography 52:2013-2026. https://doi.org/10.4319/lo.2007.52.5.2013

12. Jurafsky D, Martin JH (2020) Speech and Language Processing, 3rd edn. Stanford University

13. Kling GW, Hayhoe K, Johnson LB, et al (2003) Confronting climate change in the Great Lakes region: impacts on our communities and ecosystems

14. Latifovic R, Pouliot D (2007) Analysis of climate change impacts on lake ice phenology in Canada using the historical satellite data record. Remote Sensing of Environment 106:492-507. https://doi.org/10.1016/j.rse.2006.09.015

15. Magnuson JJ, Robertson DM, Benson BJ, et al (2000) Historical Trends in Lake and River Ice Cover in the Northern Hemisphere. Science 289:1743-1746. https://doi.org/10.1126/science.289.5485.1743

16. Ménard P, Duguay CR, Flato GM, Rouse WR (2002) Simulation of ice phenology on Great Slave Lake, Northwest Territories, Canada. Hydrological Processes 16:3691-3706. https://doi.org/10.1002/hyp.1230

17. Mittlböck M, Schemper M (1996) Explained Variation for Logistic Regression. Statistics in Medicine 15:1987-1997. https://doi.org/10.1002/(SICI)1097-0258(19961015)15:19<1987::AID-SIM318>3.0.C0;2-9

18. Oldenborgh GJ van, Hendon H, Stockdale T, et al (2021) Defining El Niño indices in a warming climate. Environ Res Lett 16:044003. https://doi.org/10.1088/1748-9326/abe9ed

19. Otto-Bliesner BL, Brady EC, Fasullo J, et al (2016) Climate Variability and Change since 850 CE: An Ensemble Approach with the Community Earth System Model. Bulletin of the American Meteorological Society 97:735-754. https://doi.org/10.1175/BAMS-D-1400233.1

20. Papers Of Princeton. Princeton University Library.

21. Rohde RA, Hausfather Z (2020) The Berkeley Earth Land/Ocean Temperature Record. Earth System Science Data 12:3469-3479. https://doi.org/10.5194/essd-12-3469-2020

Page 8/15 
22. Schröter D, Cramer W, Leemans R, et al (2005) Ecosystem Service Supply and Vulnerability to Global Change in Europe. Science 310:1333-1337. https://doi.org/10.1126/science.1115233

23. Sharma S, Blagrave K, Magnuson JJ, et al (2019) Widespread loss of lake ice around the Northern Hemisphere in a warming world. Nature Climate Change 9:227-231. https://doi.org/10.1038/s41558-018-0393-5

24. Sharma S, Magnuson JJ, Batt RD, et al (2016) Direct observations of ice seasonality reveal changes in climate over the past $320-570$ years. Sci Rep 6:25061. https://doi.org/10.1038/srep25061

25. Sharma S, Meyer MF, Culpepper J, et al (2020) Integrating Perspectives to Understand Lake Ice Dynamics in a Changing World. Journal of Geophysical Research: Biogeosciences 125:e2020JG005799. https://doi.org/10.1029/2020JG005799

26. Stasinopoulos D, Rigby R (2007) Generalized additive models for Location Scale and Shape (GAMLSS) in R. Journal of Statistical Software 23:. https://doi.org/10.18637/jss.v023.i07

27. Vavrus SJ, Wynne RH, Foley JA (1996) Measuring the sensitivity of southern Wisconsin lake ice to climate variations and lake depth using a numerical model. Limnology and Oceanography 41:822-831. https://doi.org/10.4319/lo.1996.41.5.0822

28. Weber H, Riffler M, Nõges T, Wunderle S (2016) Lake ice phenology from AVHRR data for European lakes: An automated two-step extraction method. Remote Sensing of Environment 174:329-340. https://doi.org/10.1016/j.rse.2015.12.014

29. Weyhenmeyer GA (2001) Warmer Winters: Are Planktonic Algal Populations in Sweden's Largest Lakes Affected? ambi 30:565-571. https://doi.org/10.1579/0044-7447-30.8.565

30. (1976) Lake Dredged 3 Years Ago Still Unsafe For Skating Despite Prolonged Freeze. Town Topics

\section{Figures}

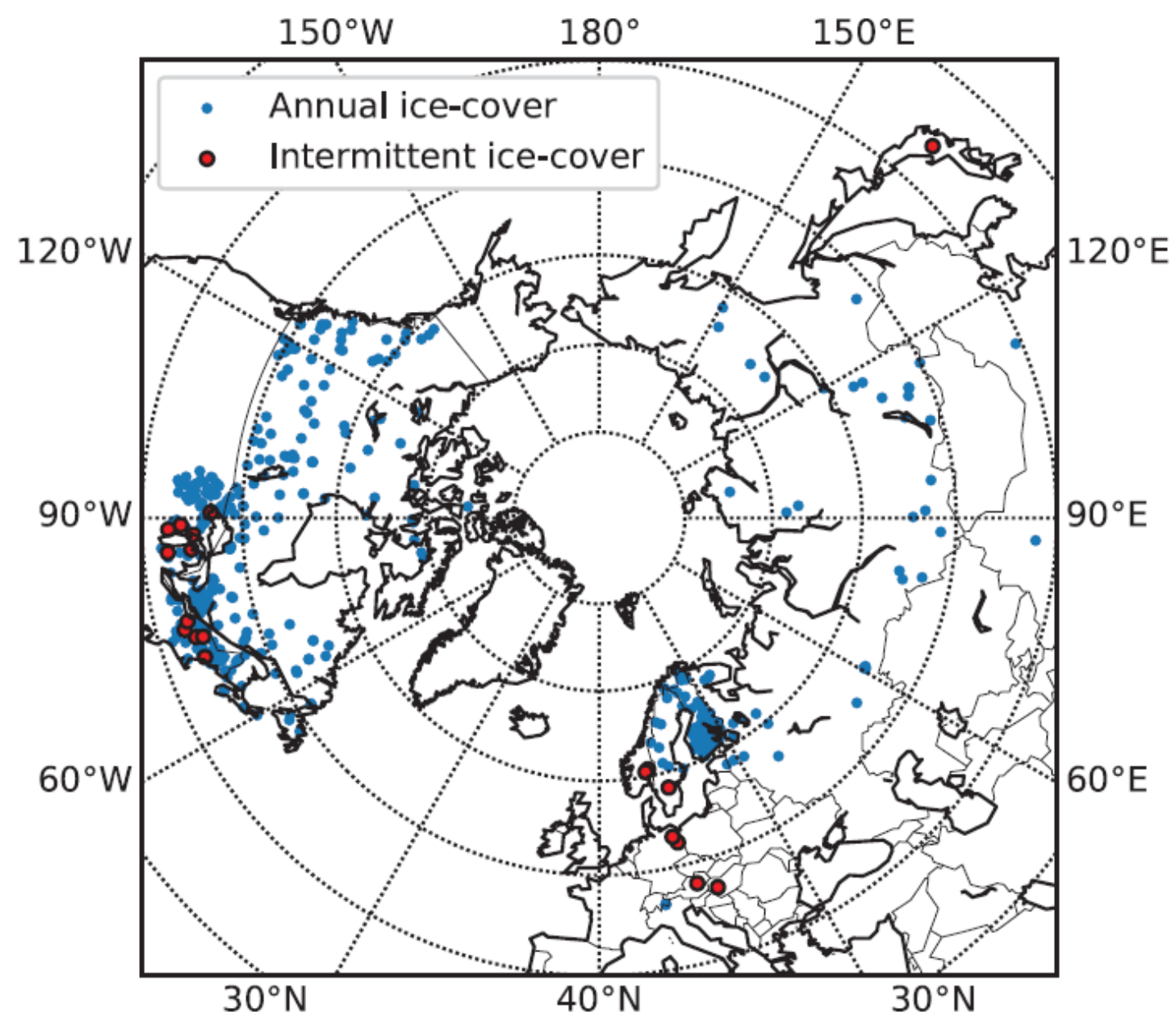

Figure 1

Geographic locations of lakes in the Global Lake and Ice Phenology Database. Intermittent ice-covered lakes are shown in red and Annual ice-covered lakes are shown in blue 
Lake Suwa (Japan)

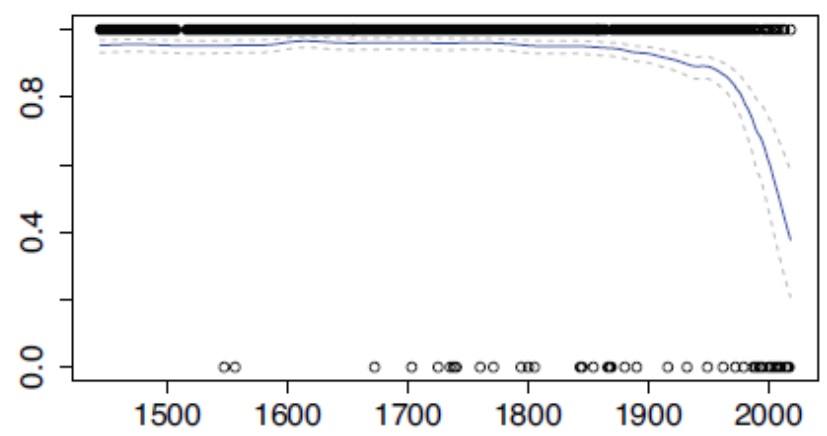

Lake Vättern (Sweden)

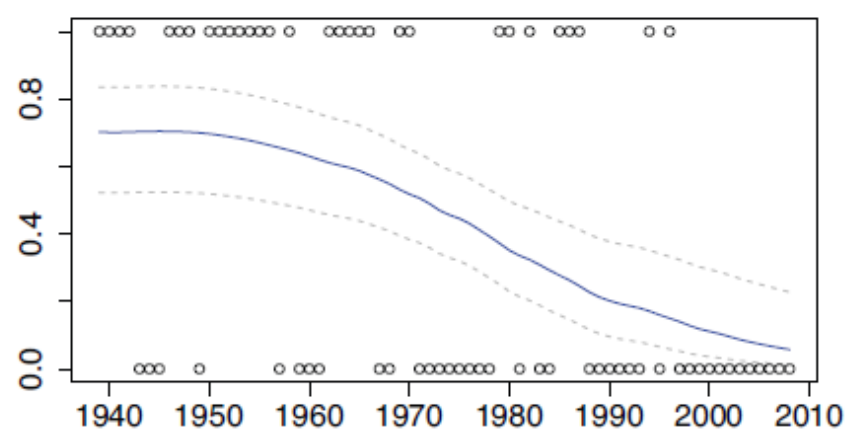

Lake Champlain (USA - NY)

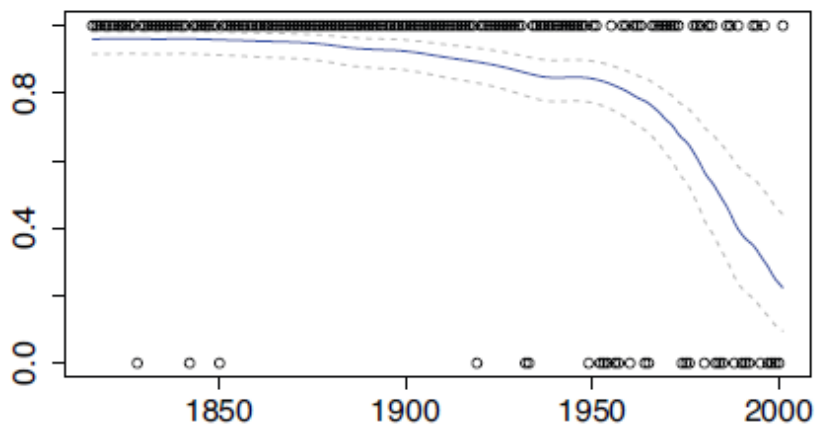

Lake Mjøsa (Norway)

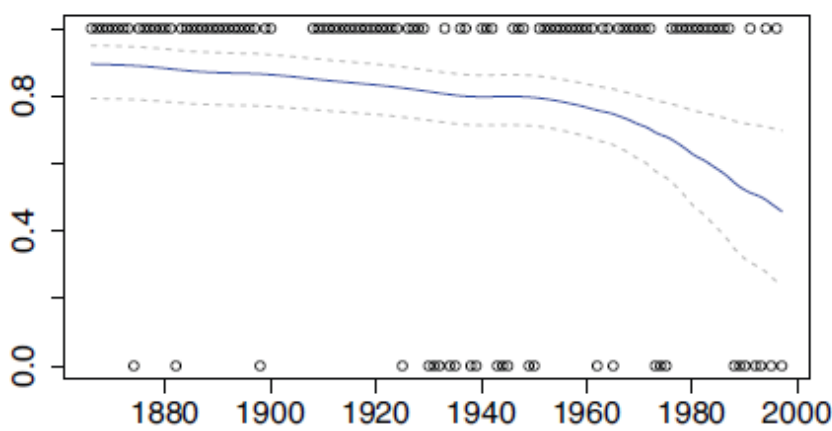

\section{Figure 2}

Time series of freeze events on Lake Champlain, Lake Mjøsa, Lake Suwa, and Lake Vättern. The blue logistic regression curve shows the predicted probability of complete winter ice-cover in a given year. The gray dashed lines show the $95 \%$ confidence interval of the probability. 
(a)

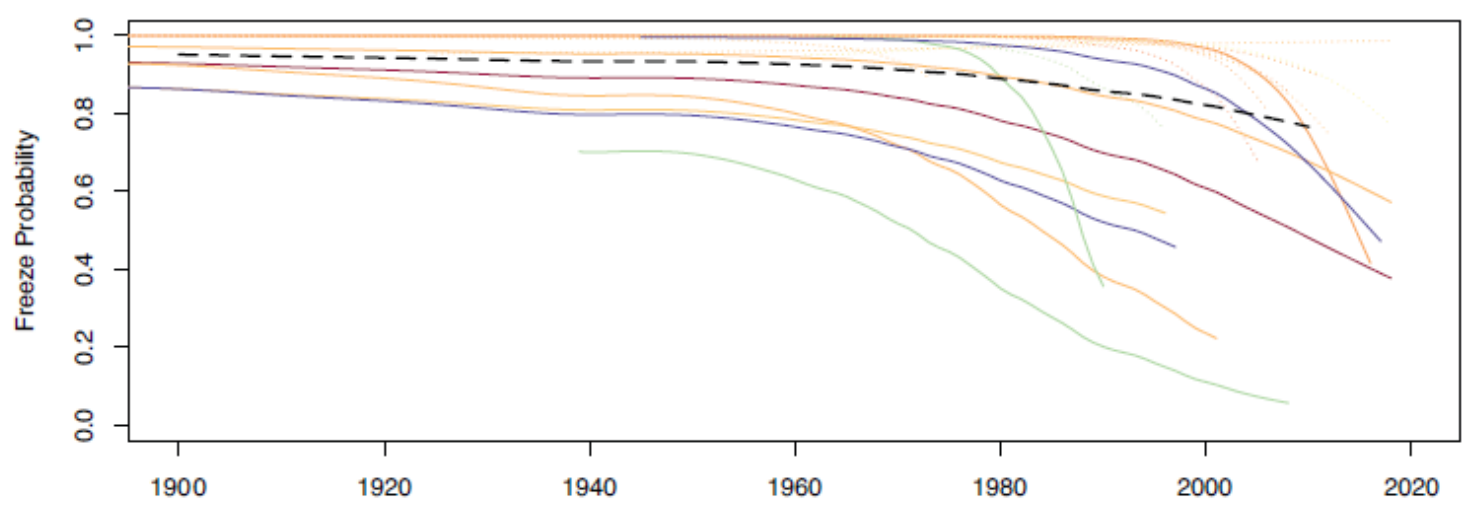

(b)

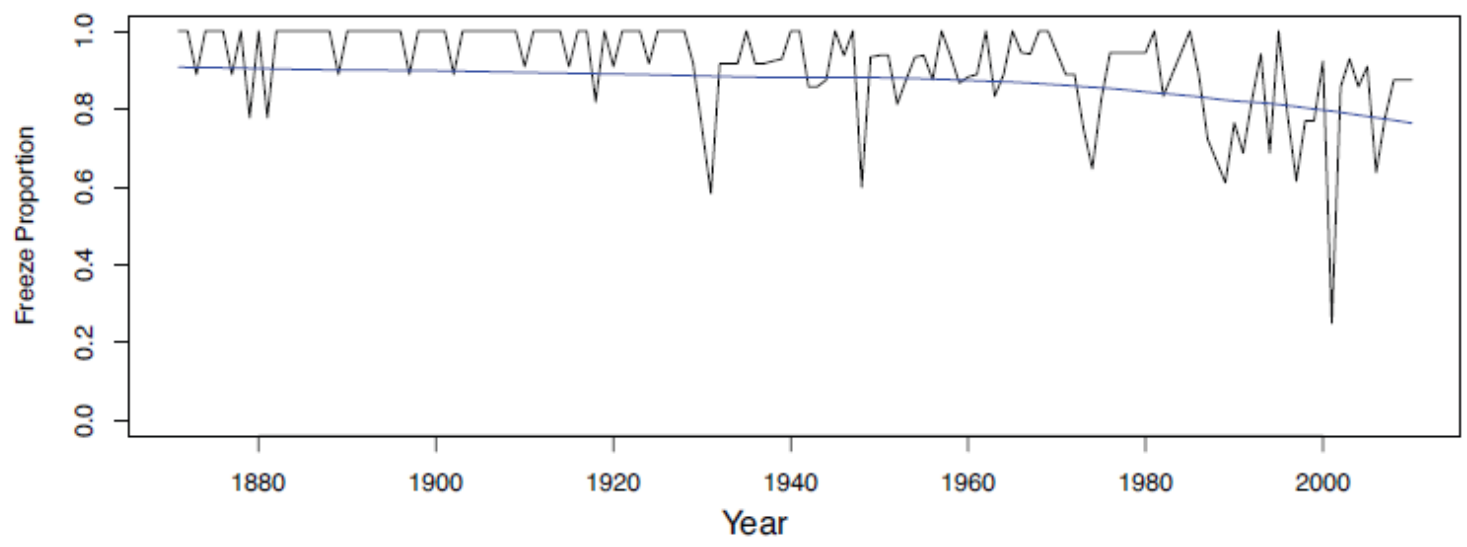

\section{Figure 3}

(a) Logistic regression curves, predicting the probability of freeze, for 19 intermittent ice-covered lakes in the northern hemisphere. Curves of similar colors represent lakes with similar latitudes, and dotted lines correspond to a fit with an insignificant p-value $(>0.05)$. The bold dashed line represents the binomial regression curve conditioned on log $\mathrm{CO} 2$ concentration and fitted against aggregate freeze proportion.

(b) Aggregate freeze proportion over time. The binomial regression curve conditioned on log $\mathrm{CO} 2$ concentration is shown in blue 


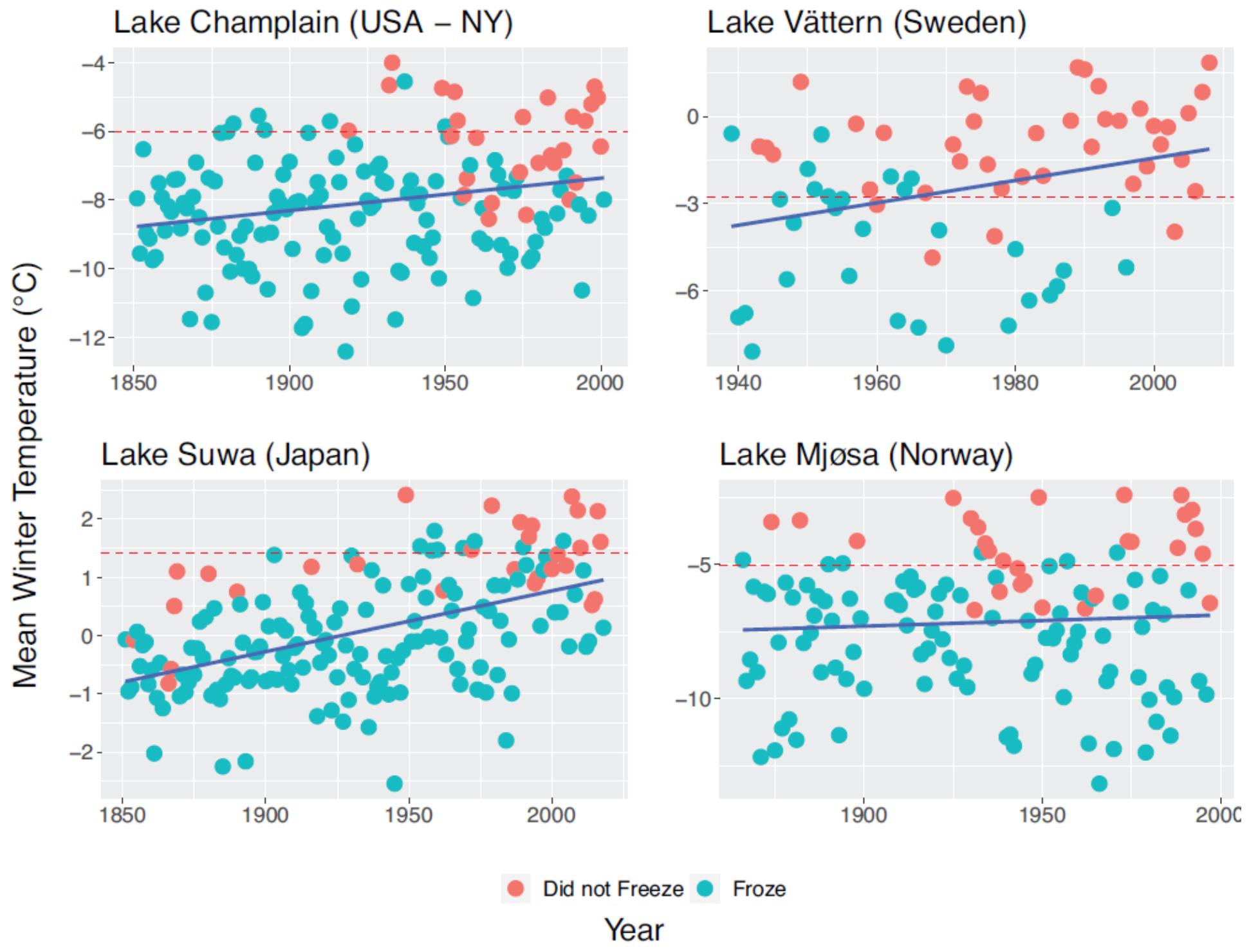

Figure 4

Scatterplots of Mean Winter Temperature over time for Lake Champlain, Lake Mjøsa, Lake Suwa, and Lake Vättern. The blue curve shows the linear trend of winter temperature. The dashed red line shows the logistic regression threshold for classifying a year as freeze or no freeze 
(a)

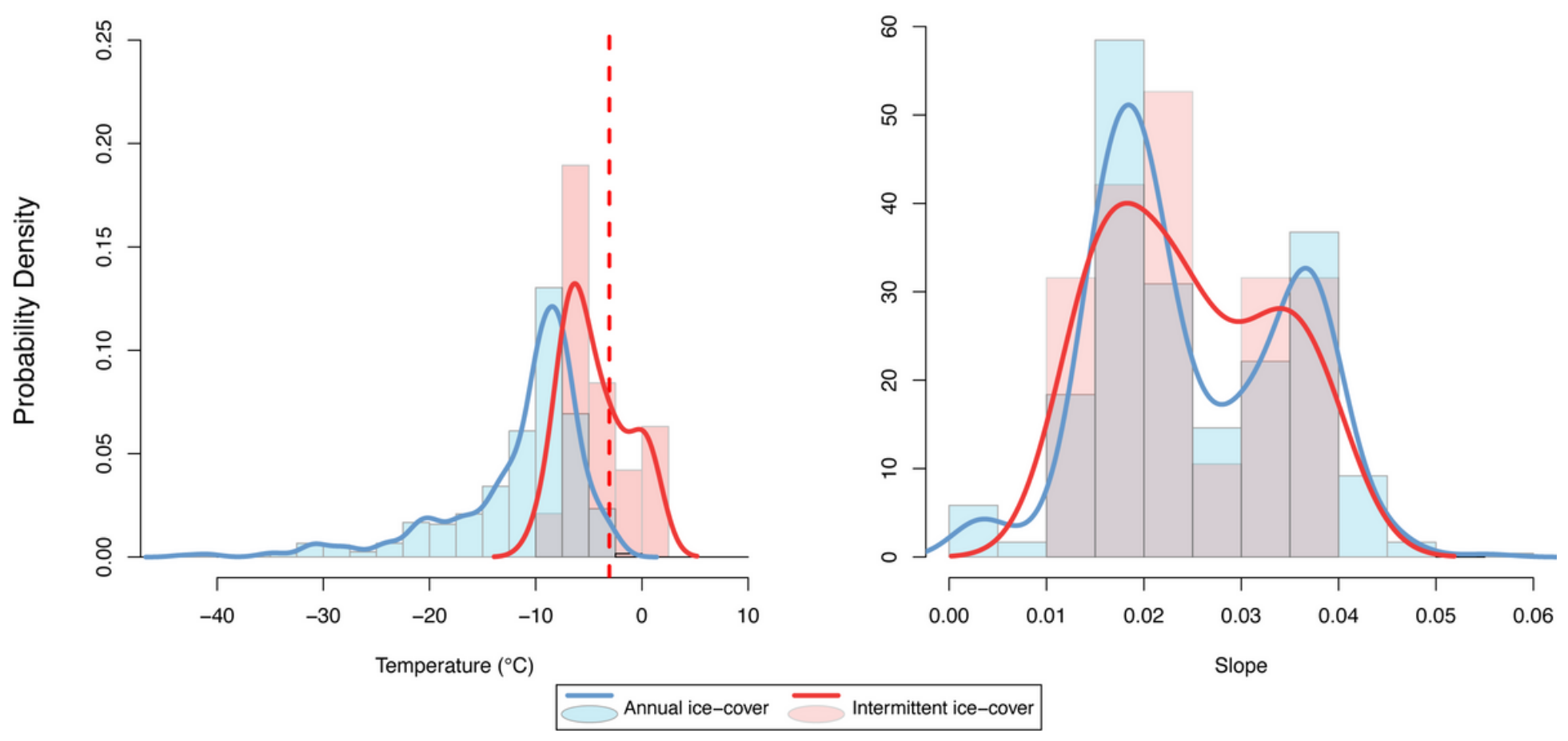

Figure 5

Histograms of the mean winter temperatures (a) and trends (b) of intermittent ice-covered lakes (blue) vs. annual ice-covered lakes (red). The dotted red line in figure a represents the mean logistic regression threshold for the 7 lakes with data for more than 4 years without freeze in their time series

\section{Lake Carnegie}

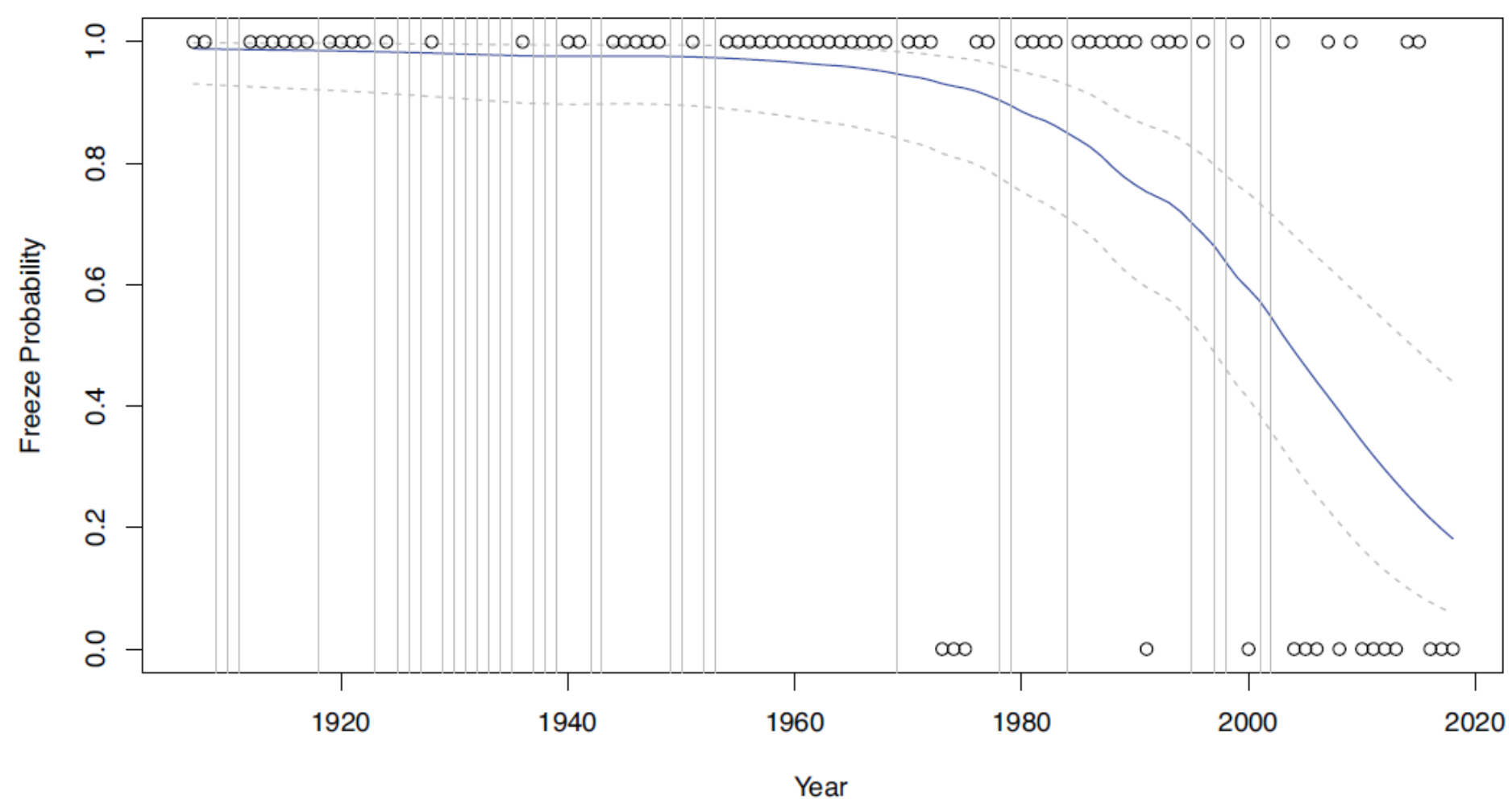

Figure 6 
Time series of ice skating on Lake Carnegie. The blue curve models the probability of documented ice skating in a given year predicted by $\log \mathrm{CO} 2$ concentration. The points represent the freeze records $(1=$ froze, $0=$ did not freeze). Vertical lines represent years with missing data

a)

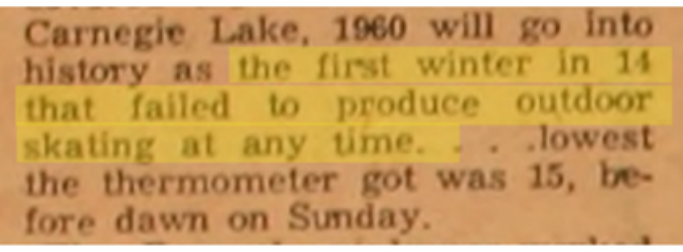

b)
ART “Those were good times, all right."
JHN "We skated around on the canal and on the lake. Sure, that was the thing to do when I was growing up. But we don't get the ice now."

c)

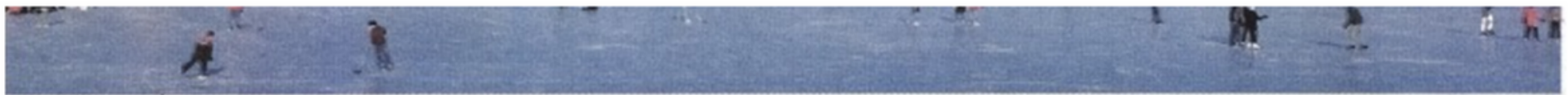

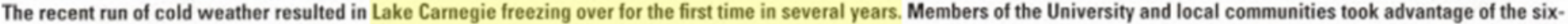

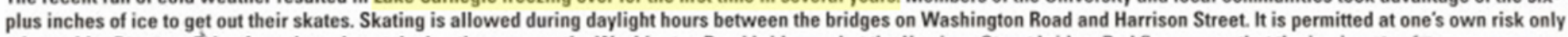
when white flags are flying from the poles at the boathouse near the Washington Road bridge and at the Harrison Street bridge. Red flags mean that the ice is not safe.
\end{abstract}

\title{
Figure 7
}

Newspaper clippings from Town Topics on Mar 13, 1960* (a), the Princeton Recollector on Dec 2, 1985 (b), and the Daily Princetonian on Feb 8, 2007 (c) *Note, there were mentions of ice skating after March 13, 1960, indicating that the lake froze later that year. 

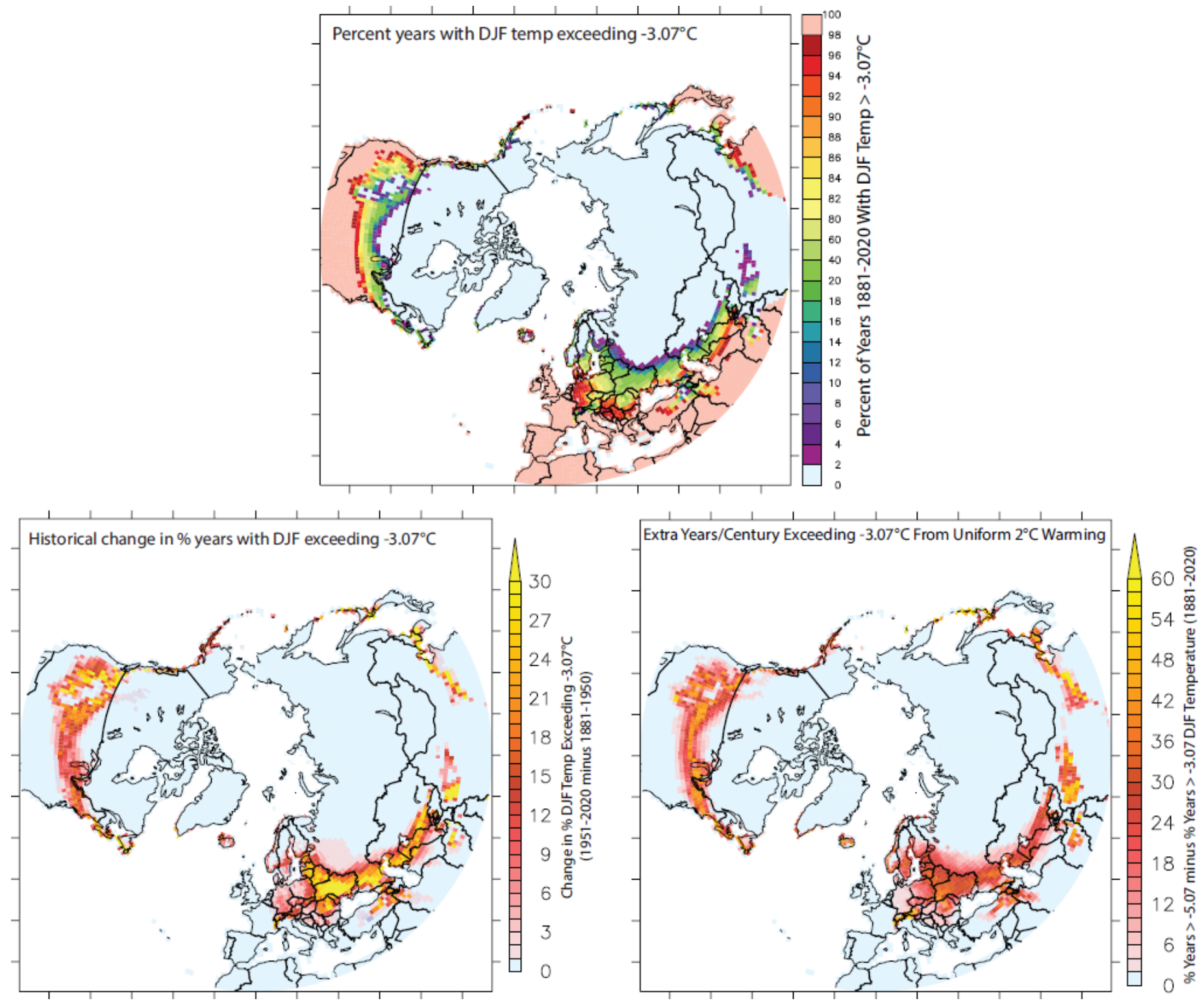

Figure 8

Map of (a) the percent of years with winter temperature exceeding the logistic regression threshold of $-3.07^{\circ} \mathrm{C}$, (b) the difference in percent of years exceeding the threshold between 1951-2020 and 1881-1950, and (c) the difference in percent of years exceeding the threshold between 1951-2020 and 1881-1950 given a uniform warming of $2{ }^{\circ} \mathrm{C}$ 